\title{
A utilização de suplementos a base de proteína vegetal e animal no treinamento de
}

\section{força}

The use of vegetable and animal protein-based supplements in strength training

El uso de suplementos a base de proteínas vegetales y animales en el entrenamiento de fuerza

Recebido: 29/09/2021 | Revisado: 04/10/2021 | Aceito: 05/10/2021 | Publicado: 06/10/2021

Ana Paula Veríssimo

ORCID: https://orcid.org/0000-0002-5331-3882 Centro Universitário Fametro, Brasil

E-mail: verissimoanapaula5@gmail.com

Mikaelen Abreu Santos

ORCID: https://orcid.org/0000-0001-6768-0977 Centro Universitário Fametro, Brasil

E-mail: mikaelenabreu@ hotmail.com

Tainara Oliveira

ORCID: https://orcid.org/0000-0003-3223-5667 Centro Universitário Fametro, Brasil E-mail: tainaraoliveira.am@gmail.com

José Carlos de Sales Ferreira

ORCID: https://orcid.org/0000-0002-1867-8229 Centro Universitário Fametro, Brasil E-mail: jcarlos.sales@gmail.com

Rebeca Sakamoto Figueiredo

ORCID: https://orcid.org/0000-0002-9819-8099 Centro Universitário Fametro, Brasil

E-mail: rebeca.figueiredo@fametro.edu.br

\begin{abstract}
Resumo
Introdução: A suplementação nutricional de proteínas se apresenta como uma necessidade importante quando se trata do treinamento de força, sendo importante o conhecimento acerca da utilização destes suplementos em consideração a sua origem, seja animal ou vegetal. Objetivo: Este estudo teve como objetivo geral analisar, através dos achados bibliográficos, a importância do uso de proteínas de origem animal e vegetal nos treinamentos de força. Metodologia: Com o levantamento bibliográfico foi possível identificar que atualmente o mercado conta com uma gama bastante diversificada de suplementos proteicos tanto de origem animal quanto vegetal, sendo os primeiros mais proeminentes em quantidade e variedade. Resultados e Discussão: Na comparação entre os resultados encontrados no que tange ao treinamento de força e os indivíduos que utilizam suplementos proteicos de origem animal e vegetal, os estudos analisados não apontaram diferença significativa entre ambos suplementos, o que indica que os dois tipos de suplementos proteicos se mostram eficazes no esperado em treinamento de força. Conclusão: não há diferença significativa nos resultados do treinamento de força considerando ambos suplementos, sendo necessário maior aprofundamento em pesquisas neste campo.
\end{abstract}

Palavras-chave: Suplementação; Proteína vegetal e animal; Treinamento de força.

\begin{abstract}
Introduction: Nutritional protein supplementation is an important need when it comes to strength training, and it is important to know about the use of these supplements in consideration of their origin, whether animal or vegetable. Objective: This study aimed to analyze, through bibliographic findings, the importance of using animal and vegetable proteins in strength training. Methodology: With the bibliographical survey, it was possible to identify that the market currently has a very diversified range of protein supplements, both of animal and vegetable origin, the first being the most prominent in quantity and variety. Results and Discussion: When comparing the results found with regard to strength training and individuals who use protein supplements of animal and vegetable origin, the studies analyzed did not show a significant difference between both supplements, which indicates that the two types of supplements Proteins are effective as expected in strength training. Conclusion: there is no significant difference in strength training results considering both supplements, requiring further research in this field.
\end{abstract}

Keywords: Supplementation; Vegetable and animal protein; Strength training. 


\begin{abstract}
Resumen
Introducción: La suplementación con proteínas nutricionales es una necesidad importante cuando se trata de entrenamiento de fuerza, y es importante conocer el uso de estos suplementos teniendo en cuenta su origen, ya sea animal o vegetal. Objetivo: Este estudio tuvo como objetivo analizar, a través de hallazgos bibliográficos, la importancia del uso de proteínas animales y vegetales en el entrenamiento de fuerza. Metodología: Con el relevamiento bibliográfico se pudo identificar que en la actualidad el mercado cuenta con una gama muy diversificada de complementos proteicos, tanto de origen animal como vegetal, siendo el primero el más destacado en cantidad y variedad. Resultados y Discusión: Al comparar los resultados encontrados con respecto al entrenamiento de fuerza y los individuos que utilizan suplementos proteicos de origen animal y vegetal, los estudios analizados no mostraron una diferencia significativa entre ambos suplementos, lo que indica que los dos tipos de suplementos Proteínas son efectivos como se esperaba en el entrenamiento de fuerza. Conclusión: no existe una diferencia significativa en los resultados del entrenamiento de fuerza considerando ambos suplementos, lo que requiere más investigación en este campo.
\end{abstract}

Palabras clave: Suplementación; Proteína vegetal y animal; Entrenamiento de fuerza.

\title{
1. Introdução
}

A busca por beleza estética, saúde e condicionamento físico tem se mostrado como uma realidade cada vez mais eminente em ambientes como consultórios de profissionais da nutrição, médicos e academias, perfazendo assim uma necessidade de uma maior compreensão de todos os aspectos que permeiam esta temática. Neste cenário é notado um destaque significativo para as questões relacionadas à necessidade de suplementação alimentar, principalmente quando se trata da relação entre este complemento através de proteínas animal e/ou vegetal direcionada ao treinamento de força.

Anterior ao entendimento acerca da importância dos suplementos alimentar faz-se mister a compreensão dos fundamentos nutricionais necessário para a manutenção da vida e da saúde do corpo humano. De acordo com Almeida e Fernandes (2011) a alimentação adequada pode ser compreendida através de diversos aspectos, desde a perspectiva nutricional até no prisma político, perpassando pela manutenção da saúde e o desempenho físico, considerando todas as possibilidades de entendimento da importância da alimentação.

Segundo Gomes e Frinhani (2017) a perspectiva política, a alimentação saudável é contemplada nas legislações constitucionais que a tratam como de acesso enquanto direito social de acordo com o artigo sexto da Constituição Federal (Brasil, 1988), juntamente com saúde, educação, moradia, entre outros. Ainda nesta seara, a alimentação adequada, de acordo com Burity et al. (2010), se apresenta como um direito humano previsto pela Declaração dos Direitos Humanos (ONU, 1998).

Em consideração aos objetivos propostos por este estudo é importante salientar os aspectos nutricionais da alimentação saudável e equilibrada. Segundo Verde e Olinda (2010), o ato de alimentar-se de forma adequada pode ser definido como o consumo de nutrientes necessários para a manutenção da vida e o equilíbrio da saúde, o que Silveira et al. (2019) complementam de forma técnica como o consumo de alimentos que supram as necessidades do organismo para seu pleno funcionamento.

Ribas et al. (2015) afirmam que sob a ótica nutricional, a alimentação equilibrada se define pela ingestão de macro e micronutrientes de forma a assegurar a nutrição do corpo, sendo os macronutrientes aqueles que se apresentam como os de fundamental importância para o organismo, sendo representados principalmente pelas proteínas, lipídios e carboidratos, e que necessitam ser ingeridos em quantidades elevadas (Marques et al., 2015), enquanto que os micronutrientes se definem como aqueles que mesmo devendo ser consumidos em quantidades menores são importantes para a nutrição do corpo, como as vitaminas e os minerais (Maia et al., 2018).

Quando o indivíduo não alcança a ingestão nutricional necessária para o bom funcionamento de seu organismo é necessário que o mesmo passe a utilizar suplementos alimentares que supram tais carências, seja elas de origem natural ou ainda em virtude de eventos externos. Neste cenário, a suplementação de proteínas se apresenta como uma das mais 
procuradas, sendo salutar o reconhecimento das origens dos suplementos disponíveis do mercado, seja animal ou vegetal (Fontenele \& Luna, 2013; Zambão, Rocco, \& Von Der Heyde, 2015).

Assim, o desenvolvimento de estudos nesta seara se mostra uma necessidade diante da importância do subsídio a trabalhos no campo da nutrição, evidenciando-se como um recurso de formação para acadêmicos e qualificação de caráter continuado para profissionais que já atuam na área. Outra justificativa para este trabalho se deu pela motivação pessoal das autoras quanto à temática considerando tanto a experiência das mesmas em relação à suplementação proteica animal e vegetal, e aos treinamentos de força.

Esta pesquisa não se constitui sumariamente como um estudo pronto e acabado, assim como não tem a pretensão de estabelecer resultados finalizados, sendo justamente o contrário, se apresentando como um ponto de partida para novos estudos que possam contribuir para a temática.

Neste sentido, este estudo tem como objetivo geral analisar, através dos achados bibliográficos, a importância do uso de proteínas de origem animal e vegetal nos treinamentos de força. Para alcance desta propositura, foram estipulados como objetivos específicos estudar os aspectos relacionados à suplementação proteica no organismo humano, identificar a relação entre o uso de suplementação proteica e o ganho de força muscular, e avaliar a importância do uso de suplementação proteica de origem animal e vegetal no desempenho físico.

\section{Metodologia}

$\mathrm{O}$ aporte teórico-metodológico utilizado na pesquisa será baseado na revisão bibliográfica, a qual se define pela identificação de literatura acerca de um determinado tema, considerando critérios previamente estabelecidos, buscando promover a sistematização de ideias entre os achados, realizando uma avaliação crítica e o confronto entre os resultados, ainda que estes tenham origem diversa. É através deste método que se apresentam as possibilidades identificação de diversos prismas acerca de uma mesma temática, o que favorece a discussão dos resultados obtidos nas pesquisas originais.

A pesquisa bibliográfica será utilizada como procedimento, por considerá-la como a mais adequada para o estudo proposto. Lakatos e Marconi (2017, p. 42) definem como o “[...] levantamento de toda a bibliografia já publicada, em forma de livros, revistas, publicações avulsas e imprensa escrita. A sua finalidade é fazer com que o pesquisador entre em contato direto com todo o material escrito sobre um determinado assunto [...]".

Trata-se de uma pesquisa de natureza básica do tipo não experimental, ou seja, o pesquisador estuda os fenômenos sem intervir de forma sistemática, ou seja, observa, registra, analisa e correlaciona fatos e variáveis sem manipulá-los (Lakatos \& Marconi, 2017). A pesquisa descritiva foi definida para o estudo proposto, visto que o seu objeto principal consiste na "[...] descrição das características de determinada população ou fenômeno ou o estabelecimento de relações entre variáveis. [...] uma de suas características mais significativas está na utilização de técnicas padronizadas de coleta de dados” (Gil, 2017, p. 28).

A escolha destes procedimentos metodológicos se justifica primordialmente pela possibilidade de compreensão dos fenômenos abordados em pesquisas já realizadas, o que se apresenta como uma forma de compreensão da realidade em que a temática se insere, confrontando as informações encontradas.

Os dados foram coletados a partir dos cruzamentos das seguintes palavras-chave: "suplementação", "proteína vegetal e animal" e "treinamento de força". Para o embasamento teórico foram incluídos, os achados científicos devidamente publicados, incluindo livros, teses, dissertações, artigos e documentos oficiais como legislações e códigos de categoria profissional.

Como critérios de inclusão foram estabelecidos a avaliação de achados entre os anos de 2010 e 2020, nas bases de dados Scielo, PubMed, Lilacs, Google Acadêmico, bem como na biblioteca da instituição, devidamente publicados na língua 
portuguesa e inglesa, e que se relacionem com os objetivos da pesquisa proposta. Como critérios de exclusão, não foram selecionados estudos sem reconhecimento científico e que se apresentassem em contradição aos objetivos da referida revisão.

\section{Resultados e Discussão}

\subsection{A suplementação proteica no organismo humano}

Diante da necessidade de compreensão acerca da necessidade de complemento alimentar, faz-se necessária a análise de aspectos relacionados à suplementação alimentar, como sua definição, quais suas necessidades e os riscos e benefícios.

Quando da ocasião da não ingestão adequada de algum dos nutrientes necessários, seja os reconhecidos como macro ou micro, é necessário que haja uma complementação destes nutrientes, o que Becker et al. (2016) definem como suplementação nutricional. Ainda sobre o conceito da mesma, Bueno Júnior (2011) complementa ao afirmar que a Sociedade Brasileira de Alimentação e Nutrição define a suplementação alimentar como o ato de complementar a alimentação de pessoas saudáveis de acordo com as necessidades nutricionais em consideração à vários aspectos como idade, carência nutricional, prática de atividades físicas, entre outros.

É notado no decorrer da análise conceitual de suplementação alimentar que a mesma se apresenta como uma necessidade em complementar as carências nutricionais de indivíduos em decorrência de questões diversas sejam de ordem natural ou ainda externa.

Segundo Fontenele e Luna (2013), assim como é importante a conceituação de suplementação alimentar, é imprescindível o reconhecimento legal da mesma diante das legislações que regulamentam esta prática, considerando assim a importância da mesma, sendo possível citar desde a criação a ANVISA como agência reguladora destes suprimentos até instruções normativas mais atuais que direcionam a fabricação, comércio e consumo destes produtos.

De posse dos conceitos de suplementos alimentares faz-se mister o levantamento dos tipos destes suplementos, sua função e exemplificação, conforme Tabela 1:

Tabela 1 - Tipos de suplementos alimentares.

\begin{tabular}{|c|c|c|}
\hline Tipo de suplementos & Função & Exemplos \\
\hline Hipercalóricos & $\begin{array}{c}\text { Auxílio no } \\
\text { ganho de peso }\end{array}$ & $\begin{array}{c}\text { Suplementos a base de carboidratos como a } \\
\text { maltodextrina e dextrose }\end{array}$ \\
\hline Proteícos & $\begin{array}{c}\text { Aumento da massa } \\
\text { magra }\end{array}$ & $\begin{array}{c}\text { Suplementos a base de proteínas do leite } \\
\text { como a whey protein }\end{array}$ \\
\hline Termogênicos & $\begin{array}{c}\text { Redução de peso com a } \\
\text { aceleração do } \\
\text { metabolismo }\end{array}$ & $\begin{array}{c}\text { Suplementos a base de cafeína, gengibre ou } \\
\text { sinefrina, por exemplo }\end{array}$ \\
\hline Antioxidantes & $\begin{array}{c}\text { Atuação do processo de } \\
\text { envelhecimento }\end{array}$ & $\begin{array}{c}\text { Suplementos a base de vitaminas e } \\
\text { Astaxantina, entre outros }\end{array}$ \\
\hline Hormonais & $\begin{array}{c}\text { Regulação do sistema } \\
\text { hormonal }\end{array}$ & $\begin{array}{c}\text { Suplementos a base de estrogênio, } \\
\text { testosterona, entre outros hormônios }\end{array}$ \\
\hline
\end{tabular}

Fonte: Luchese et. al (2014); Lessa et al. (2020); Souza, Drummond (2018); Santos et al. (2020); Filho et al. (2012); Peruchi et al. (2017); Mara et al. (2014), adaptado pelas autoras.

É observado no reconhecimento dos tipos de suplementação nutricional que os mesmos são desenvolvidos em conformidade com as necessidades de cada indivíduo, uma vez que são direcionadas para cada função, bem como é notado que existe uma gama de suplementos que atendem cada uma destas necessidades.

De acordo com Pontes, Pereira e Ferreira (2021), dentre as suplementações nutricionais mais conhecidas é salutar a apresentação da complementação de proteínas, a qual, segundo Lessa et al. (2020) é necessária diante da importância deste nutriente que nem sempre é consumido de forma natural na alimentação, devendo ser suplementado. 
Neste sentido, é observado os suplementos proteicos tem uma importância fundamental diante de fatores diversos, sendo necessário citar em primeira instância a carência natural de proteínas via alimentar e em segunda instância em razão da necessidade funcional e estética do corpo, com o ganho de massa magra ou ainda melhoria dos treinamentos físicos, por exemplo.

De acordo com Zambão, Rocco e Von Der Heyde (2015), é salutar o destaque de que tal necessidade de suplementação ocorre principalmente quando se trata de indivíduos praticantes de treinamentos físicos, o que Lusano e Quaresma (2021) afirmam ocorrer tanto no nível de atividades físicas regulares em academias quando dos que praticam treinos mais elaborados que demandam um condicionamento e desempenho físico mais consistente. Filho (2020) complementa ainda que não se deve ignorar a procura por tais suplementos por aqueles que buscam a construção muscular estética.

Observa-se novamente que a suplementação de proteínas no corpo humano quando relacionada à necessidades externas atende uma gama de indivíduos com objetivos bastante diversificados, sendo notado desde aqueles que buscam condicionamento muscular e físico até aqueles que estão a procura de construção muscular estética.

Silva e Souza (2016) afirmam que atualmente é possível encontrar uma série de suplementos proteicos utilizados com o propósito de auxiliar na construção de massa magra, o que Freitas et al (2015) elucida que auxiliam tanto na estética quanto no desempenho físico e nos treinamentos de força, sendo que, de acordo com Bezerra e Macedo (2013) e Santos, Maciel e Meneghetti (2011), é possível classificá-los em conformidade com sua fonte de extração.

Novamente é apresentada a aplicabilidade das suplementações proteicas junto ao organismo humano, destacando a necessidade de contemplar suas origens como parâmetro para identificação de suas propriedades e desempenho.

Os suplementos proteicos podem ser classificados como de origem animal e vegetal, sendo possível contemplar suas especificidades na Tabela 2: 
Tabela 2 - Tipos de suplementos proteicos de acordo com sua origem.

\begin{tabular}{|c|c|c|}
\hline Origem & Tipos & Características \\
\hline \multirow{5}{*}{ Animal } & Caseína & $\begin{array}{l}\text { Fosfoproteína encontrada no leite voltado para o ganho de massa muscular. A } \\
\text { caseína hidrolisada é de rápida absorção ao passo que a caseína micelar é } \\
\text { absorvida de forma mais lenta }\end{array}$ \\
\hline & Albumina & $\begin{array}{l}\text { Originada da proteína do ovo, de fácil digestão e absorção pelo organismo } \\
\text { voltada para a nutrição do organismo, fornecimento de energia e hipertrofia } \\
\text { muscular }\end{array}$ \\
\hline & Whey & $\begin{array}{l}\text { Composta principalmente de alfa-globulina e beta- globulina, é extraída do } \\
\text { leite e utilizada para a construção muscular e aumento da força. São } \\
\text { reconhecidos três tipos de Whey, sendo a concentrada com cerca de } 75 \% \text { de } \\
\text { proteína, a isolada em que há uma concentração de } 90 \% \text { de proteínas e a } \\
\text { hidrolisada que se caracteriza pelo processamento prévio da proteína do leite }\end{array}$ \\
\hline & BCAA & $\begin{array}{l}\text { Aminoácidos de cadeia ramificada atuam na redução da fadiga pós } \\
\text { treinamento físico e na recuperação muscular, contribuindo para a hipertrofia }\end{array}$ \\
\hline & $\begin{array}{l}\text { Derivados } \\
\text { da carne }\end{array}$ & $\begin{array}{l}\text { Proteínas originadas da carne são alternativas para intolerantes ao leite e } \\
\text { ovos, sendo compostas por aminoácidos encontrados nas carnes }\end{array}$ \\
\hline \multirow{4}{*}{ Vegetal } & Soja & $\begin{array}{l}\text { Rica em aminoácidos, pode se apresentar de forma concentrada e isolada, } \\
\text { sendo de elevada absorção e opção para indivíduos veganos }\end{array}$ \\
\hline & Trigo & $\begin{array}{l}\text { Possui grande quantidade de leucina, isoleucina e valina, apresentando-se na } \\
\text { forma hidrolisada e concentrada, com elevada digestibilidade e absorção, } \\
\text { contribuindo para a hipertrofia muscular }\end{array}$ \\
\hline & Arroz & $\begin{array}{l}\text { Rica em aminoácidos e de elevada absorção se revela uma alternativa viável } \\
\text { diante da necessidade de pessoas impedidas de ingestão de proteína animal }\end{array}$ \\
\hline & Ervilha & $\begin{array}{l}\text { Apresentada no formato concentrado e hidrolisado, é rica em aminoácidos de } \\
\text { alta qualidade, sendo enriquecido com diversas vitaminas como ferro }\end{array}$ \\
\hline
\end{tabular}

Fonte: Crivelin et al. (2018); Tavano et al. (2017); Cardoso, Leonhardt (2017); Scarlato et al. (2016); Leitzke et al. (2017); Correa, Navarro (2014); Gonçalves, Silva (2010); Carreira et al. (2011); Santos et al. (2018).

$\mathrm{Na}$ oportunidade de análise dos tipos de suplementos proteicos a partir de sua origem a observância de alguns pontos se mostra imprescindível, sendo o primeiro aspecto a discrepância em relação a quantidade de exemplos entre os grupos, seguido das congruências entre eles e por fim o advento dos suplementos de origem vegetal.

Nota-se que os suplementos de proteínas animal se mostram em maior quantidade no mercado, sendo inclusive mais popularizados e consumidos que os de origem vegetal, o que pode ser relacionado ao custo, teor de proteínas e atendimento maior a demanda comercial, o que não significa invalidar os de origem vegetal.

Em relação aos pontos em comum notados nas características dos tipos de suplementos analisados, observou-se que, independentemente da fonte, todos os suplementos atendem as características necessárias para sua função, sendo ricos em aminoácidos que promovem a síntese proteica, e que de igual forma se apresentam em versões diversificadas, como a concentrada e hidrolisada, por exemplo.

Notou-se também que há uma maior quantidade de suplementos de origem vegetal no mercado quando comparado a tempos passados, o que infere a adequação da produção as necessidades de indivíduos que não ingerem produtos de origem animal, seja por imposições orgânicas como doenças e alergias, seja por opção de uma dieta vegetariana ou vegana.

\subsection{A relação entre o treinamento de força e suplementação proteica}

O treinamento de força é apresentado como aquele que objetiva melhoria do condicionamento muscular com o desenvolvimento da força e da hipertrofia muscular, favorecendo assim a modificação corporal como aumento da massa magra, aumento da resistência, melhoria do sistema imunológico, promoção da saúde, retardo de envelhecimento e melhorias 
estéticas (Fleck \&Kraemer, 2017, Martins et al., 2017; Materko \& Hallehandre, 2018; Gomes, Triani, \& Silva, 2017; Santos, Martins \& Ferreira, 2021).

De acordo com Gomes, Triani e Silva (2017) é imprescindível que o treinamento de força seja compreendido para além do reconhecido sobre o ganho de massa muscular com o intuito isolado de desempenho físico, o que Santos, Martins e Ferreira (2021) afirma se apresentar como um limitante dos objetivos do treinamento de força, uma vez que seus benefícios podem ser notados em diversas áreas.

Neste sentido é percebido que o treinamento de força não se limita somente a sua definição de forma básica, mas está interligada a diversos resultados positivos para o corpo humano, o que justifica a necessidade de desenvolvimento de métodos que potencializem esse tipo de treino, bem como o reconhecimento de possíveis suplementos que auxiliem o mesmo.

Martins et al. (2017) elucida que os treinamentos de força apresentam como benefícios a melhora do condicionamento físico e por conseguinte o aumento da resistência ao esforço, bem como e o retardo do processo de envelhecimento. Materko e Hallehandre (2018) categorizam ainda que os treinamentos de força contribuem para melhorias estéticas consideráveis, com a redução de índices de gordura quando associados à outros exercícios, e definição muscular.

Nota-se que dentre os primeiros benefícios possíveis de interligação com o treinamento de força, é possível destacar que o condicionamento físico sofre melhora e impacta assim no desempenho do indivíduo, sendo ainda relacionado ao aprimoramento físico sob o ponto de vista estético, sendo estes benefícios associados não somente à saúde física, mas também mental, uma vez que favorece tanto a autoestima quanto o porte físico.

Fleck e Kraemer (2017) elucidam que o potencial dos treinamentos de força contribui para a hipertrofia muscular e o ganho de massa magra, o que torna possível sua relação com o consumo e suplementação de proteínas considerando a contribuição destas para a construção e recuperação muscular diante dos treinos de força.

Em consideração ao proposto por este estudo é importante observar que um potencial benefício do treinamento de força é o ganho de massa magra principalmente em função da redução do percentual de gordura corporal, o que ocorre principalmente quando associado a exercícios aeróbicos, sendo que este contexto é amplificado quando há a associação dos exercícios de força à ingestão de suplementos proteicos, seja de origem animal ou vegetal, o que auxilia na recuperação muscular pós treinos, aumentando assim a massa magra.

\subsection{Suplementação proteica animal e vegetal no treinamento de força}

Quando se trata mais especificamente dos treinamentos de força e a utilização de suplementos proteicos de origem tanto animal quanto vegetal é possível afirmar que estes se apresentam como efetivos, o que favorece potencialmente o ganho de massa magra, tonificação muscular, entre outros (Faria, 2018; Souza et al., 2018; Cordeiro et al., 2018; Souza \& CargninCarvalho, 2018).

Observa-se, portanto, que ambas as fontes de suplementos proteicos, quando associados à protocolos de treinamento de força, possuem resultados favoráveis aos indivíduos, sendo notados aspectos semelhantes entre ambas, o que aponta para a inferência da possível adequação suplementar em conformidade com as necessidades e possibilidades de cada pessoa, não interferindo nos resultados.

Os suplementos proteicos de origem vegetal são apresentados como instrumentos capazes de contribuir para hipertrofia muscular e por conseguinte auxilia nos treinamentos de força (Linberg et al., 2021). É percebida que a maior potência dos suplementos de proteína de origem vegetal se dá em razão da sua capacidade de regeneração muscular, sendo sua administração mais utilizada após os treinamentos (Assis et al., 2017; Molin et al., 2019; Souza et al., 2020; Macedo et al., 2020). 
Quando da análise mais detalhada dos suplementos proteicos de origem vegetal é notório que os mesmos se dedicam mais a regeneração muscular na ocasião de sua ingestão pós treinamento de força, uma vez que contribui de forma mais rápida para a síntese proteica nos músculos após a execução do protocolo de força.

No que tange aos suplementos proteicos de origem animal é notado que quando se trata do treinamento de força estes se assemelham aos achados pertinentes aos suplementos vegetais, porém é observado que os suplementos de origem animal possuem maiores concentrações de creatina muscular, o que favorece o desempenho muscular e, portanto, o treinamento de força (Crivelin et al., 2018; Silva et al., 2018; Medeiros, Daronco \& Balsan, 2019; Camargo, Doneda \& Oliveira, 2019).

Observa-se que os suplementos de proteínas de origem animal são reconhecidos potencialmente em razão da síntese proteica nos músculos pós treino, mas que também apresentam melhores resultados quando se trata do desempenho dos mesmos, o que é avaliado pela dose de creatina em sua composição.

De acordo com os achados de Tavares Filho (2020) quando associados o uso de suplementos proteicos e melhores resultados nos treinamentos de força, é possível afirmar que não há resultados que apontem influência direta nesta relação, porém é viável afirmar que são notados acréscimos de massa magra nos indivíduos analisados. Os achados observados no desenvolvimento deste estudo demonstraram que a alimentação rica em proteínas associada à suplementação proteica teve resultados sutilmente positivos no ganho de massa magra ao passo que os indivíduos submetidos a menores quantidades de proteínas não tiveram o mesmo resultado.

Nota-se que o uso de suplementos nutricionais proteicos junto a treinamentos de força, ainda mais quando associados à alimentação igualmente equilibrada deste nutriente, se mostra uma estratégia exitosa na construção muscular e no ganho de massa magra, o que se configura um ponto positivo para os indivíduos que fazem uso desta combinação.

Santos (2017) anteriormente encontrou resultado diferente, sendo que o protocolo se deu igualmente associou o uso de suplementos proteicos e treinamentos de força, sendo adicionado o uso de carboidratos, o que não demandou diferentes resultados. Os achados deste estudo apontaram que não houve discrepância entre o grupo de indivíduos estudados que associaram carboidrato e proteínas suplementadas aos que utilizaram somente suplementos proteicos, sendo submetidos à treinos de força, não apresentando diferenças nos resultados comparativos.

É observado que quando a associação de suplementos proteicos e treinamento de força é realizado com dieta rica de carboidratos não apresentam resultados significativos quando comparados aos protocolos comuns sem ingestão de carboidratos, sendo possível então avaliar que o consumo de carboidratos não está associado diretamente a resultados positivos neste contexto.

No que tange à comparação entre a suplementação proteica considerando a origem dos complementos, Fernandes (2017) afirmou que quando analisados indivíduos que suplementaram em grupos diferentes com o soro do leite ou proteínas de soja, foi notado que não houve diferença notável nos resultados quando comparadas as fontes de proteínas utilizadas, sendo que ambos os grupos tiveram melhoria no ganho de massa e na força após a participação nos protocolos estipulados.

Estes achados possibilitam observar que independente da origem das proteínas dos suplementos nutricionais, seja vegetal ou animal, os resultados quando questionados o ganho de massa muscular e a força após treinamentos direcionados para tal se mostram semelhantes, não sendo necessariamente possível apontar um suplemento mais eficaz que o outro.

\section{Considerações Finais}

No processo de análise da utilização de suplementos de proteínas de origem animal e vegetal junto à treinamento de força foi possível averiguar uma série de aspectos relacionados à esta temática, o que proporcionou a construção de bases mais aprofundadas de conhecimentos sobre a comparação entre ambos os tipos de suplementos. 
Ao compreender a importância da suplementação de proteínas, independentemente de sua origem, junto a pessoas que fazem treinos de força, notou-se que este complemento nutricional se revela necessário para o processo de hipertrofia muscular, o que impacta diretamente nos resultados esperados por estes indivíduos, seja sob a ótica funcional ou estética.

E por fim, diante dos resultados identificados em estudos comparativos entre os resultados do uso de suplementos proteicos de origem animal e vegetal em treinamentos de força, concluiu-se que não diferença significativa nos resultados considerando ambos suplementos, sendo necessário maior aprofundamento em pesquisas neste campo.

\section{Referências}

Almeida, C. A. N., \& Fernandes, G. (2011). A importância do porcionamento na alimentação balanceada. International Journal of Nutrology, 4(03), 018-023.

Assis, L. O., et al. (2017). Determinação da atividade inibitória de enzimas digestivas em suplementos vendidos no comercio internacional à base de proteína vegetal. RBNE-Revista Brasileira de Nutrição Esportiva, 11(67), 925-933.

Becker, L. K., et al. (2016). Efeitos da suplementação nutricional sobre a composição corporal e o desempenho de atletas: uma revisão. RBNE-Revista Brasileira de Nutrição Esportiva, 10(55), 93-111.

Bezerra, C. C., \& Macedo, E. M. C. (2013). Consumo de suplementos a base de proteína e o conhecimento sobre alimentos proteicos por praticantes de musculação. RBNE-Revista Brasileira de Nutrição Esportiva, 7(40).

Brasil. Constituição Federal da República Federativa do Brasil. Brasília: Casa Civil, 1988.

Bueno Jr, Carlos Roberto. (2011). Suplementação nutricional em praticantes de atividade física: mitos e verdades. Revista Brasileira de Nutrição Esportiva, 5(26), 97-99.

Burity, V., et al. (2010). Direito humano à alimentação adequada no contexto da segurança alimentar e nutricional. Brasília: Abrandh.

Camargo, L., Doneda, D. D., \& Oliveira, V. R. (2019). A utilização do whey protein na suplementação de idosos. Revista Brasileira de Ciências do Envelhecimento Humano, 16(2), 46-46.

Cardoso, K. F., \& Leonhardt, V. (2017). Avaliação do consumo de suplementos proteicos por praticantes de musculação em uma academia de PlanaltinaDF. Revista Brasileira de Nutrição Esportiva, 11(68), 1083-1091

Carreira, R. L., et al. (2011). Perfil peptídico de hidrolisados proteicos da farinha de trigo. Pesquisa Agropecuária Tropical, 41, 481-489.

Cordeiro, S. A., et al. (2018). Efeitos da Suplementação de Creatina no Treinamento de Força. International Journal of Nutrology, 11(S 01$)$, Trab345.

Corrêa, D. B., \& Navarro, A. C. (2014). Distribuição de resposta dos praticantes de atividade física com relação à utilização de suplementos alimentares e o acompanhamento nutricional em uma academia de Natal/RN. Revista Brasileira de Nutrição Esportiva, 8(43), 5.

Crivelin, V. X., et al. (2018). Suplementos alimentares: perfil do consumidor e composição química. Revista Brasileira de Nutrição Esportiva, 12(69), 30-36.

Faria, Dayane Pêdra Batista. (2018). Suplementação de creatina no ganho de força e hipertrofia muscular em praticantes de treinamento de força: uma breve revisão narrativa. Revista Eletrônica Acervo Saúde/Electronic Journal Collection Health ISSN, 2178, 2091.

Fernandes, Alan Lins. (2017). Efeitos da suplementação de proteína de soja versus proteína do soro de leite em idosos com pré-fragilidade e fragilidade submetidos a um programa de treinamento de força. Tese (Doutorado) Escola de Educação Física e Esporte da Universidade de São Paulo, $124 \mathrm{f}$.

FILHO, A. D., et al. (2012). Efeitos de um produto termogênico sobre parâmetros bioquímicos e morfológicos relacionados à saúde: um estudo de caso. Revista Brasileira de Nutrição Esportiva, 6(33), 1.

Fleck, S. J., \& Kraemer, W. J. (2017). Fundamentos do treinamento de força muscular. Artmed Editora.

Fontenele, M. L., \& Luna, G. I. Regulamentação da Suplementação Nutricional no Brasil. Acta de Ciências e Saúde, 1(2), 82-94.

Freitas, H. R., et al. (2015). Avaliação da rotulagem e informação nutricional de suplementos proteicos importados no Brasil. RBNE-Revista Brasileira de Nutrição Esportiva, 9(49), 14-24.

Gil, Antônio Carlos. (2017). Como elaborar projetos de pesquisa. (6a ed.), Atlas.

Gomes, C. V., Frinhani, F. M. D. (2017). Alimentação saudável como direito humano à saúde: uma análise das normas regulamentadoras da produção de alimentos orgânicos. Leopoldianum, 43(121), 22-22.

Gomes, R. M., Da Silva Triani, F., \& Da Silva, C. A. F. (2017). Conhecimento nutricional de praticantes de treinamento de força. RBNE-Revista Brasileira De Nutrição Esportiva, 11(65), 610-617.

Lakatos, E. M., \& Marconi, M. A. Fundamentos da metodologia científica. (8a ed.), Atlas.

Leitzke, P. S. O., et al. (2017). Whey protein como alternativa de suplemento proteico para indivíduos intolerantes à lactose. Revista Brasileira de Nutrição Esportiva, 11(67), 851-855. 
Lessa, B. S. B., et al. (2020). Avaliação do consumo de suplementação protéica em desportistas com foco em hipertrofia. RBNE-Revista Brasileira de Nutrição Esportiva, 14(88), 445-453.

Limberg, B. C., et al. (2021). Desenvolvimento de uma goma proteica vegetal. Fag Journal Of Health (FJH), 3(1), 34-37.

Lucchese, R., et al. (2014). Aconselhamento nutricional como forma de prevenção ao abuso de álcool pós cirurgia bariátrica: um estudo de caso. Enciclopédia Biosfera, 10(19).

Luzano, J. P., \& Dos Santos Quaresma, M. V. L. (2021). Efeitos da suplementação proteica sobre a força e a massa muscular de idosos: uma revisão narrativa da literatura. Brazilian Journal of Development, 7(5), 52102-52111.

Macedo, A. S., et al. (2020). O uso de suplementos alimentares por praticantes de atividade física no município de Juiz de Fora-MG e análise renal. Revista Eletrônica Acervo Saúde, 45, e2950-e2950.

Maia, A. V., et al. (2018). Ingestão dietética de macro e micronutrientes em atletas de powerlifting pré-completicação. RBNE-Revista Brasileira De Nutrição Esportiva, 12(74), 715-723.

Marques, N. F., et al. (2015). Consumo alimentar e conhecimento nutricional de praticantes de musculação do município de Itaqui-RS. Revista Brasileira de Nutrição Esportiva, 9(52), 288-297.

Martins, A., et al. (2017). Força muscular em mulheres praticantes de treinamento de força e de treinamento concorrente: um estudo descritivo comparativo. Revista de Educação Física/Journal of Physical Education, 86(2).

Materko, W., \& Hallehandre, L. (2018). Efeito placebo no desempenho da força muscular em homens experientes em treinamento de força. RBNE-Revista Brasileira de Nutrição Esportiva, 12(71), 374-379.

Medeiros, A., Daronco, L. S. E., \& Balsan, L. A. G. (2019). Uso de suplementos por praticantes de musculação em academias. Revista Brasileira de Nutrição Esportiva, 13(80), 601-608.

Molin, T. R. D., et al. (2019). Marco regulatório dos suplementos alimentares e o desafio à saúde pública. Revista de Saúde Pública, 53.

ONU. Declaração Universal dos Direitos Humanos. (1998). Adotada e proclamada pela resolução 217 A (III) da Assembléia Geral das Nações Unidas em 10 de dezembro de 1948. Brasília: UNESCO.

Peruchi, R. F. P., et al. (2017). Suplementação Nutricional Em Idosos (Aminoácidos, Proteínas, Pufas, Vitamina De Zinco) Com Ênfase Em Sarcopenia: Uma Revisão Sistemática. Revista UNINGÁ Review, 30(3).

Pontes, C., Pereira, H. C., \& Ferreira, J. C. (2021). A importância da suplementação proteica no paciente bariátrico. Revista Ibero-Americana de Humanidades, Ciências e Educação, 7(5), 450-461.

Ribas, M. R., et al. (2015). Ingestão de macro e micronutrientes de praticantes de musculação de ambos os sexos. RBNE-Revista Brasileira de Nutrição Esportiva, 9(49), 91-99.

Santos, J. F. C., Maciel, F. H. S., Menegetti, D. (2011). Consumo de suplementos proteicos e expressão da raiva em praticantes de musculação. Revista da Educação Física/UEM, 22, 623-635.

Santos, J. P. C., Martins, G. H., \& Ferreira, J. C. (2021). O uso da creatina no treinamento de força e na melhoria do desempenho físico. Research, Society and Development, 10(11), e59101119410-e59101119410.

Santos, L. G. C., et al. Efeitos da associação entre atividade física e suplementação de proteína na capacidade funcional de idosos: uma revisão. Brazilian Journal of Health Review, v. 3, n. 2, p. 3609-3621, 2020.

Santos, P. C. (2017). Efeitos do treinamento de força associado à suplementação de proteína e carboidrato na força e hipertrofia muscular de homens jovens destreinados. Dissertação (Mestrado) Universidade Estadual Paulista "Júlio de Mesquita Filho". Faculdade de Ciências Farmacêuticas. Programa de Pós Graduação em Alimentos e Nutrição, $41 \mathrm{f}$.

Santos, S. S. (2018). A suplementação com proteína da soja para a hipertrofia muscular. Revela, 2, 183 -206.

Scarlato, R. C., et al. (2016). Determinação do teor de proteínas e carboidratos totais em suplementos tipo Whey Protein. Revista do Instituto Adolfo Lutz, 75, 01-07.

Silva, F. R., et al. (2018). Perfil nutricional e uso de suplementos alimentares: estudo com adultos praticantes de musculação. Motricidade, 14(1), 271-278.

Silva, L. V., \& De Souza, S. V. C. Qualidade de suplementos proteicos: avaliação da composição e rotulagem. Revista do Instituto Adolfo Lutz, 75, 01-17, 2016 .

Silveira, M. G., et al. (2019). Conhecimentos de acadêmicos de Nutrição sobre alimentação saudável e Nutrição Esportiva. RBNE-Revista Brasileira De Nutrição Esportiva, 13(78), 227-235.

Sousa, B. A., Drummond, M. G. (2018). O impacto da suplementação proteica na hipertrofia muscular de desportistas. Revista Brasileira de Ciências da Vida, $6(05), 129-144$.

Souza, Guilherme Silva Freire et al. Efeitos da Suplementação de Creatina no Treinamento de Força. International Journal of Nutrology, $11(01)$, p. Trab346.

Souza, I. R., Cargnin-Carvalho, A. (2018). Consumo de suplementos nutricionais nas academias da cidade de Braço do Norte-SC. RBNE-Revista Brasileira de Nutrição Esportiva, 12(70), 213-221. 
Research, Society and Development, v. 10, n. 13, e117101321225, 2021

(CC BY 4.0) | ISSN 2525-3409 | DOI: http://dx.doi.org/10.33448/rsd-v10i13.21225

Souza, R. P., et al. (2020). Investigação da rotulagem e informação nutricional de suplementos protéicos voltados para atletas veganos. Research, Society and Development, 9(8), e106985398-e106985398.

Tavano, O. L., et al. (2017). Composição e digestibilidade proteica de suplementos alimentícios contendo proteína de soro de leite (whey protein). Revista do Instituto de Laticínios Cândido Tostes, 72(3), 131-138.

Tavares Filho, José Henrique da Costa. (2020). Estudo de dois padrões de distribuição proteica sobre hipertrofia e força muscular em homens jovens treinados submetidos a treinamento de força. Dissertação (Mestrado em Nutrição) - Universidade Federal de Pernambuco, Recife.

Verde, S. M. M. L., \& Olinda, Q. B. (2010). Educação nutricional: uma ferramenta para alimentação saudável. Rev. bras. promoç. saúde (Impr.).

Zambão, J. L., Rocco, C. S., \& Von Der Heyde, M. E. D. (2015). Relação entre a suplementação de proteína do soro do leite e hipertrofia muscular: uma revisão. RBNE-Revista Brasileira de Nutrição Esportiva, 9(50), 179-192. 